\title{
HEAVY-ION COLLISIONS AND THE NUCLEAR EQUATION OF STATE
}

\author{
Progress Report to the US DEPARTMENT OF ENERgY \\ FOR THE PERIOD \\ AUGUST 15, 1991 - MARCH 1992
}

Grant DE-FG02-89ER40531

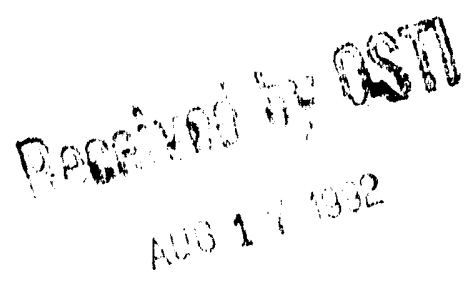

\author{
Declan Keane \\ Department of Physics \\ Kent State University \\ Kent, OH 44242
}

\section{DISCLAIMER}

\footnotetext{
This report was prepared as an account of work sponsored by an agency of the United States Government. Neither the United States Government nor any agency thereof, nor any of their employees, makes any warranty, express or implied, or assumes any legal liability or responsibility for the accuracy, completeness, or usefulness of any information, apparatus, product, or process disclosed, or represents that its use would not infringe privately owned rights. Reference herein to any specific commercial product, process, or service by trade name, trademark, manufacturer, or otherwise does not necessarily constitute or imply its endorsement, recommendgtion, or favoring by the United States Government or any agency thereof. The views and opinions of authors expressed herein do not necessarily state or reflect those of the United States Government or any agency thereof.
} 


\section{Table of Contents}

Page

Abstract . . . . . . . . . . . . . . . . . . . . . . 1

1. Bevalac Streamer Chamber Analysis . . . . . . . . . . . . . . . . . . 2

2. The EOS Time Projection Chamber . . . . . . . . . . . . . . . . . . . 2

2.1 The EOS Pad Monitor . . . . . . . . . . . . . . . . . . . . . . 4

2.2 Particle Identification . . . . . . . . . . . . . . . . . . . . 4

2.3 Plans for Experimental Running . . . . . . . . . . . . . . . . . 6

3. The STAR Detector . . . . . . . . . . . . . . . . . . . 6

$3.1 \mathrm{~K}_{S}^{0}$ Interferometry . . . . . . . . . . . . . . . . . . . . . . 6

$3.2 \mathrm{~d} E / \mathrm{d} x$ Resolution of the STAR TPC . . . . . . . . . . . . . . . . . . . 7

3.3 Plans for Coming Year . . . . . . . . . . . . . . . . . . . . . 7

4. The NA49 Experiment . . . . . . . . . . . . . . . . . . . . . . 9

5. Other Activities . . . . . . . . . . . . . . . . . . . . . 10

5.1 The Neutron Flow Experiment 848H . . . . . . . . . . . . . . . . . . . . 10

5.2 Collaboration with Harbin . . . . . . . . . . . . . . . . . . . . . . . 11

6. Publications for 12-Month Period Ending April 1992 . . . . . . . . . . . . . . . 12

6.1 Papers in Refereed Journals . . . . . . . . . . . . . . . . . . 12

6.2 Conference Proceedings . . . . . . . . . . . . . . . . . . . 13

6.3 Technical Reports and Abstracts . . . . . . . . . . . . . . . . 13

7. Budget . . . . . . . . . . . . . . . . . . . . . . 15

7.1 Budget Summary . . . . . . . . . . . . . . . . . . . 15

7.2 Budget Explanation . . . . . . . . . . . . . . . . . . 16

7.3 Unobligated Balance . . . . . . . . . . . . . . . . . . . . 18

7.4 Current and Pending Support . . . . . . . . . . . . . . . . . 18

Appendix

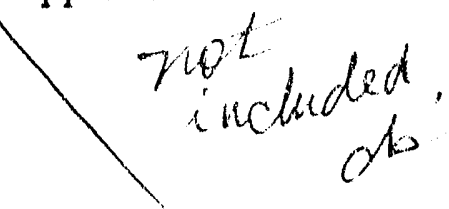




\begin{abstract}
The overall goal of this project is to atudy nucleus-nucleus collisions experimentally at intermediate and relativistic energies, with emphasis on messurement and interpretation of correlation effects that provide insight into the nuclear phase diagram and the nuclear equation of state. During the past year, the PI has been on leave at Lawrence Berkeley Lab and has worked on this research project full-time. A large fraction of the effort of the PI and graduate students has gone into preparing for experiments using the Time Projection Chamber at LBL's Bevalac accelerator; in March 1992, this device successfully took data in production mode for the first time, and the first physics analysis is now under way. The PI has carried out simulations that belp to define the physics performance and engineering specifications of the recently-approved STAR detector for the Relativistic Heavy Ion Collider, and has identified a new capability of this device with the potential for being an important quark-gluon plasma signature. A Postdoctoral Fellow, jointly supported by this grant and Kent State University, has been recruited to augment these efforts. Since May 1991, 11 journal papers have been published or submitted for publication; 2 conference proceedings and 9 reports or abstracts have also been published during the past year. One paper in Phys. Rev. Lett., one in Phys. Rev. C, and one conference proceedings are based on the thesis project of one of the PI's Ph.D. students who is expected to graduate later this year. Partly in response to the impending closure of the Bevalac, the PI's group has recently joined the NA49 experiment at CERN.
\end{abstract}




\section{Bevalac Streamer Chamber Analysis}

Analysis of data from the Bevalac streamer chamber has accounted for about one-third of the research effort of the PI over the past several years. This activity has allowed productivity in terms of publications to be maintained while devoting effort to projecis like the EOS TPC and STAR; moreover, the streamer chamber is an excellent testing-ground for at least some of the $4 \pi$ physics that EOS will open up. At the time of writing, we have just completed the first physics-quality run of the EOS TPC, and so this marks the end of the streamer chamber analysis effort. The two streamer chamber analyses described in last year's report were published during the current reporting period (publications [iii] and [V], section 6.1).

Although it is not proposed to expend any further effort on streamer chamber analysis, work already "in the pipeline" will result in some streamer chamber putlications during the coming year. Most notable among these is a very promising new analysis that constitutes part of the dissertation project of Jinghua Jiang, one of the two graduate students supported by this grant. The underlying idea has important implications for our understanding of the equation of state, as demonstrated by the fact that our paper has been accepted by Phys. Rev. Lett. despite being based on previously-reported decade-old streamer chamber data. Our paper points out that no previous study of the sideward flow effect has ruled out the possibility that the effect is dominated by a small number of correlated fragments in each event, as opposed to being a true collective motion to which most or all fragments contribute. We introduce two separate methods of characterizing "collectivity" - the percentage of fragments that carry a component of the collective motion. Collectivity is a new degree freedom that is independent of the magnitude of the flow correlation (the quantity normally measured in studies of sideward flow). The scope of this initial study using a small sample of streamer chamber events is rather limited, but it opens the way for a wide-ranging systematic investigation of the collectivity of the sideward flow phenomenon using the EOS TPC. The preprint of our paper is included in the Appendix.

\section{T'he EOS Time Projection Chamber}

Since June 1990, Kent State graduate student Yiping Shao bas been resident continuously at LBL to work on EOS; in June 1991, student Alan Scott also took up residence at LBL to work full-time on EOS. Also in June 1991, the PI's one year leave at LBL began, with EOS as a major focus of effort. 


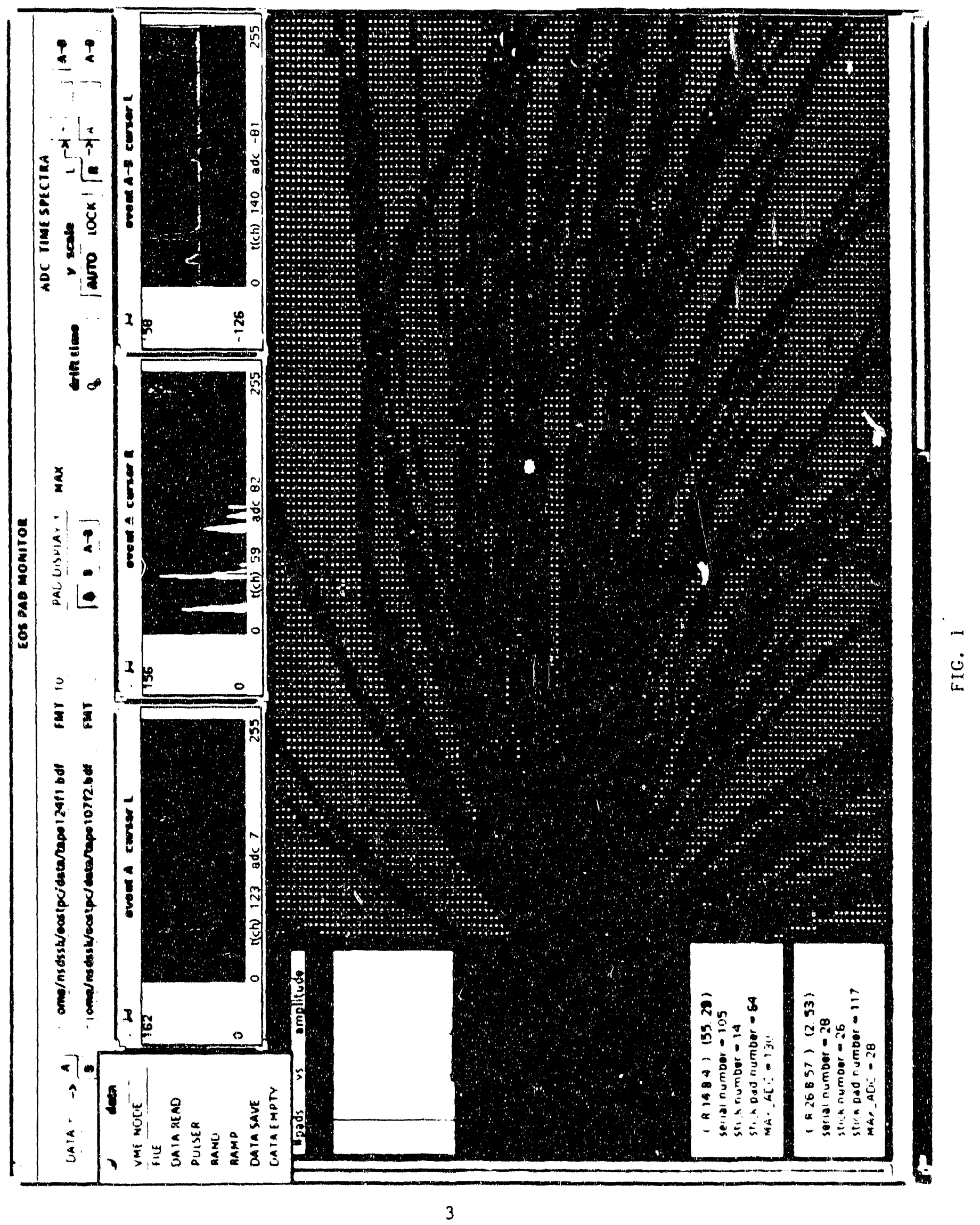




\subsection{The EOS Pad Monitor}

One of the more tangible Kent State contributions to EOS during the past year has been in development of the Pad Monitor software. The original concept and program shell was initiated by LBL's Howard Wieman. Yiping Shoo then took over the task of continuing the development of the code and of customizing it to she EOS environment. More than half the current $~ 9000$-line program was written by Yiping Shao, and new features are still being implemented. (A separate offshoot of Howard Wieman's original core program was indepenciently customized to the NA35 environment.)

The Pad Monitor program runs on SUN SPARCstations and functions as a powerful and intuitive tool for examining all formats of TPC data on-line (or can operate on a disk file) with a much shorter time-lag than the normal analysis chain. During running of the experiment, it has served as our primary means for monitoring the performance of the TPC. It also proved very useful during testing of the read-out electronics. All user commands are input using the mouse, and most of the information is presented in one composite display window, as shown in Fig 1. The main pad plane display can operate on the maximum or the mean or the r.m.s. amplitude for all time-buckets collected on that pad; if the selected parameter exceeds a threshold set by the cursor of the "\# pads vs amplitude" window, the pad is displayed in red. The "data" pop-up window allows two events from the same source or from different sources to be loaded simultaneously, and the pad display can operate on the amplitude difference between the two events. This feature is useful for testing pedestal subtraction. Other options include projecting all time-buckets onto the pad plane, or selecting a time-slice. Two individual pad signals can be examined in greater detail through the amplitude versus time spectra shown in the upper part of the display. These spectra bave mouse-controlled zoom features, and the color-matched message boxes on the lower left of the display provide additional diagnostic information for the selected pads.

\subsection{Particle Identification}

Another area of responsibility for ous group has been software for particle identification. The two upper panels of Fig. 2 show truncated mean $d E / d x$ versus rigidity for fragments from collisions of $\mathrm{Ne}+\mathrm{NaF}$ and $\mathrm{Ca}+\mathrm{Cs}$, and the lower panels separately show the identified protons and deuterons for the $\mathrm{Ca}+\mathrm{Ca}$ data. We are already close to having an automated procedure for maintaining calibration of the particle identification in the face of drifting gas gain and changes in operating conditions from run to run, and for at least some of the data from our recent run, 

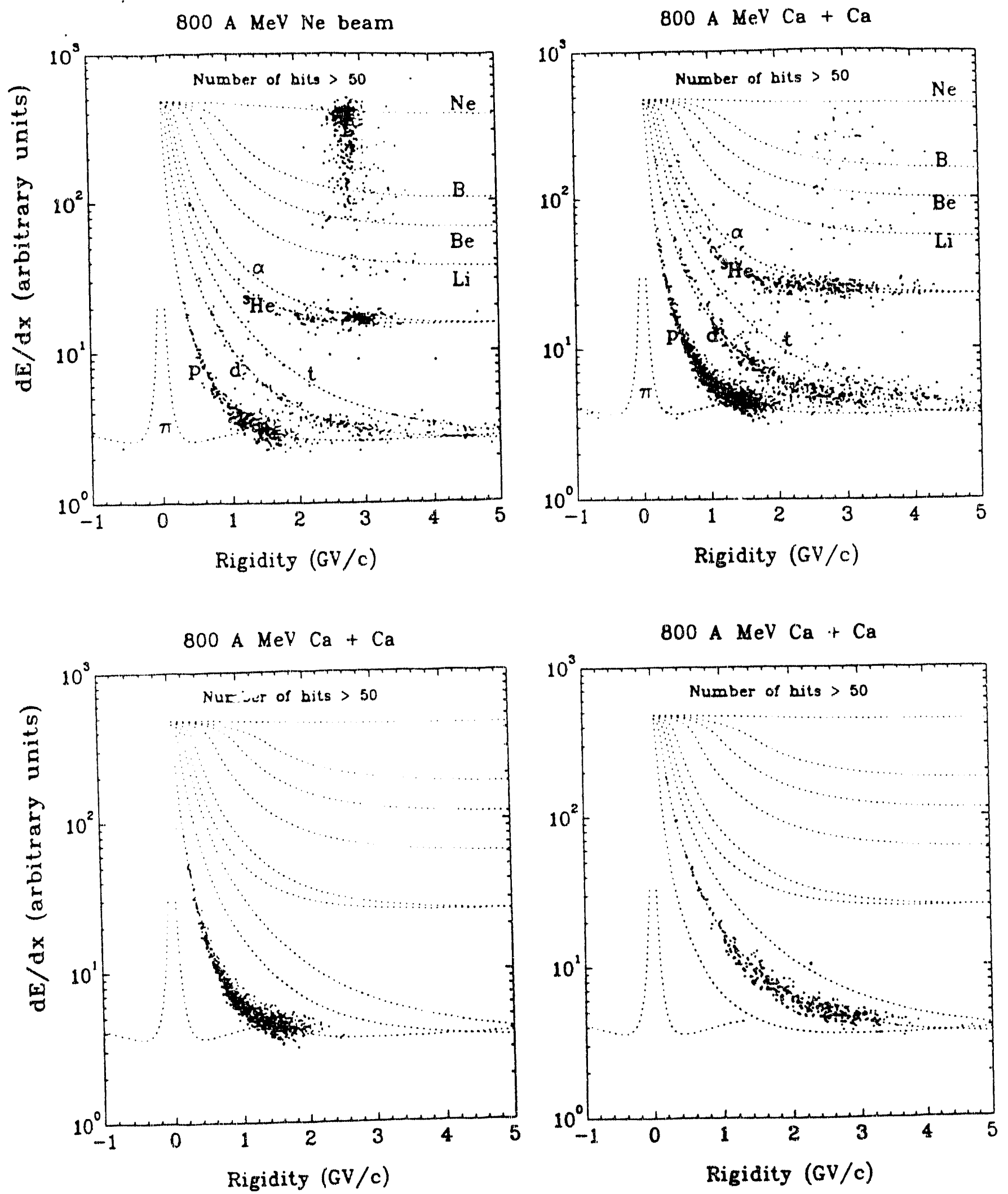

FIG. 2: The two upper panels show mean truncated $d E / d x$ versus rigidity for fragments from collisions of $\mathrm{Ne}+\mathrm{NaF}$ and $\mathrm{Ca}+\mathrm{Ca}$; the lower panels show the identified protons and deuterons for the $\mathrm{Ca}+\mathrm{Ca}$ data. 
we have achieved the full $\mathrm{d} E / \mathrm{d} x$ resolution expected on the basis of scaling the final performance of other TPCs.

\subsection{Plans for Experimental Running}

The Kent State beam-time proposal, one of three approved by the PAC in 1990, focused on two aspects of the study of the equation of state at lower Bevalac energies: first, the flow correlations at 200 or $250 \mathrm{MeV} /$ nucleon - low enough so that fragments heavier than ${ }^{4} \mathrm{He}$ are produced in significant numbers in the participant region, and the hydrogen and helium isotopes can be separated with optimum efficiency; second, the energy dependence of the global event characteristics going even lower in beam energy, with emphasis on combinations like $\mathrm{Au}+\mathrm{Au}$ at 100 and $150 \mathrm{MeV} /$ nucleon, which are out of reach of the MSU cyclotrons. Because of the impending termination of the Bevalac research program within less than a year from now, we have deferred the second of these two goals. This decision was taken in light of the unique physics opportunities at the higher Bevalac energies, and the probable need to experiment with optimizing detector performance at and below $150 \mathrm{MeV} /$ nucleon. On the other hand, as a result of our recent progress in interpretation of high-order correlations and collectivity (see section 1 and the Appendix), prospects for new and exciting physics associated with the first goal have improved. We plan to devote $100+$ hours of beam time to this part of the program even in the more pessimistic scenario for the future of the Bevalar.

\section{The STAR Detector}

Activity in support of STAR has increased significantly during the past 12 months, despite the fact that the PI's streamer chamber effort began to wind-down only during the latter part of the reporting period. This increase has been helped by the fact that the PI has had no teaching or university service duties, and has just been further augmented by the recent hiring of Dr. Marvin Justice as a postdoc, supported jointly by this grant and by Kent State Unjversity. Marvin Justice is a UC Berkeley graduate whose thesis experiment, under the direction of Luciano Moretto, involved measurement of Coulomb fragmentation of uranium projectiles at the Bevalac. He also contributed to several other projects, including experiments at the Bevalac's JANUS spectrometer and a muon-catalyzed fusion experiment at PSI in Switzerland.

\section{1 $\mathrm{K}_{S}^{0}$ Interferometry}

One of the PI's contributions to STAP during the past year has been in developing the idea of $K_{\text {short }}^{0}$ interferometry, and in carrying out simulations that demonstrate the feasibility and 
unique advantages of such measurements using a combination of information from the STAR TPC and the Silicon Vertex Tracker. One of the main virtues of interferometry measurements at RHIC will be the possibility to observe a lengthening of the source lifetime, attributable to specific heat effects in a plasma model. Kaons offer significant advantages over pions for this purpose; resonances mimic a plasma by increasing the apparent size and lifetime of the source, and this distortion is less severe for ksons. However, Coulomb repulsion is much stronger for kaons, and so neutral kaons offer the best of both worlds. In addition, neutral kaons are immune to 2-tracl resolution effects that result in serious distortion of charged-particle interferometry measurements when source sizes are large. Further details and references can be found in STAR Note \#47, included in the Appendix to this report.

\section{2 $\mathrm{d} E / \mathrm{d} x$ Resolution of the STAR TPC}

Another recent project has been simulation of the $\mathrm{d} E / \mathrm{d} x$ performance of the STAR TPC. This work is a natural outgrowth from similar work done for EOS, and like the $\mathrm{K}_{S}^{0}$ simulation, is a prerequisite for defining detector specifications needed for the Conceptual Design Report. Fig. 3 shows the expected distributions of mean truncated $\mathrm{d} E / \mathrm{d} x$ versus momentum for $\mathrm{Si}+\mathrm{Si}$ collisions; the performance for $\mathrm{Au}+\mathrm{Au}$ is currently worse, but bas been improving steadily as the tracking software is adjusted and improved. Fig. 3 indicates that the expected flux of electrons (from $\pi^{0} \mathrm{~s}$ and direct $\gamma \mathrm{s}$ ) is low enough that there is little motivation for further improving $\mathrm{d} E / \mathrm{d} x$ resolution for the purpose of separating electrons from pions and kaons. Likewise, the spectra of pions, kaons and protons are such that relatively few particles populate momenta in the region of the relativistic rise, where improved $\mathrm{d} E / \mathrm{d} x$ resolution might otherwise have some utility. These considerations have an impact on engineering specifications such as anode wire tolerances which determine the uniformity of the gas gain.

\subsection{Plans for Coming Year}

Looking ahead to the coming year, our group has undertaken to develop an integrated monitor and control system for the STAR TPC anode voltage supplies. This will probably use as a foundation the SUN SPARCstation software that Yiping Shao is currently writing for EOS as a replacement for the passive terminal control feature of the LeCroy $1440 \mathrm{HV}$ chassis. A powerful and flexible user interface can be implemented using the SPARCatation, and it permits keeping records of the monitored parameters. A major shortcoming of the 1440 is the fact that it cannot. monitor currents at the nanoamp level, as typically drawn by a group of TPC anode wires. We will build an external $\mathrm{nA}$ current monitor for several hundred channels and integrate its output 


\section{$\mathrm{Si}+\mathrm{Si}$}

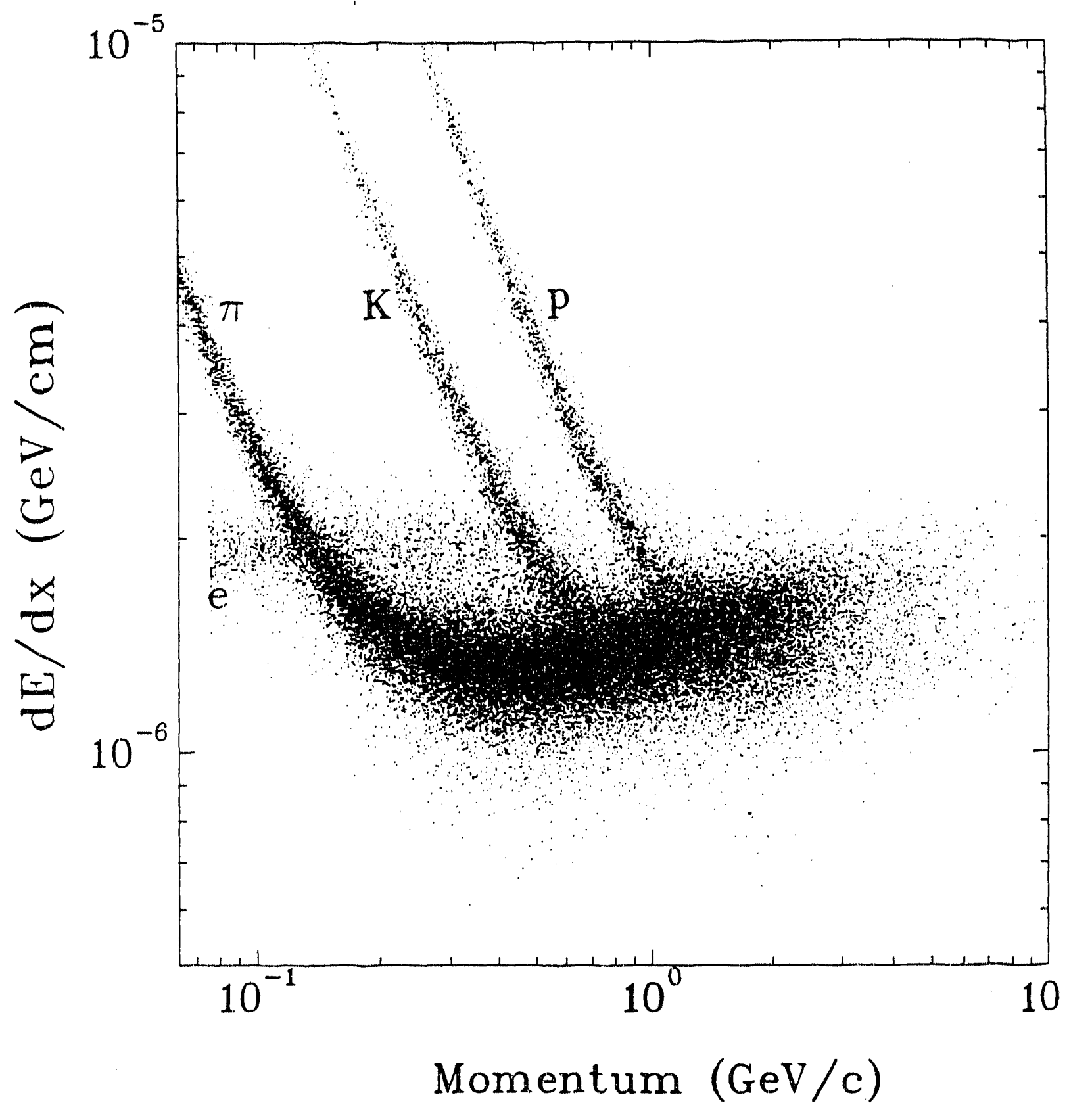

FIG. 3: Expected distribution of $d E / d x$ vs. momentum for $\mathrm{Si}+\mathrm{Si}$ collisions in the STAR TPC. 
into the monitor/control software. The $\mathrm{nA}$ current monitoring and logging function is needed for at least a limited number of channels on a short timescale, to facilitate testing of TPC endcap prototypes. The hardware construction phase of this project will begin at Kent this fall, after the PI has ret urned from the current one-year leave at LBL.

The new generation of tracking detectors planned for experiments at RHIC are faced with the formidable task of pattern recognition and tracking in a very high multiplicity environment. Marvin Justice has chosen to work on innovative approaches to the tracking problem, such as the "elastic" algorithm advocated by Miklos Gyulassy. He plans to evaluate and improve the new algorithms in the realistic environment of the EOS TPC data as well as using STAR simulations.

\section{The NA49 Experiment}

The impending shutdown of Nuclear Science research at the Bevalac has far-reaching implications for the research plan laid out in last year's proposal, and prompted the PI's decision (made within the past few weeks) to join the NA49 Pb beam experiment at CERN. NA49 is an obvious bridge between EOS and STAR in terms of both timing and physics. The most compelling consideration in this decision, aside from the intrinsic scientific importance of NA49, is that as the PI's current graduate students finish-up (Jinghua Jiang this year, Yiping Shao probably in 1993, and Alan Scott in '93 or '94), there would be no experimental dissertation project available for new students for several years without such an intermediate-term project. Another consideration was that Art Poskanzer invited our group to join NA49 at this time, prompted by a recommendation from the DOE that he should recruit additional university groups from the US. This recommendation from DOE is interpreted as a signal that the resources needed to take on this new commitment are available.

During the past year, about two-thirds of the PI's research effort has been devoted to EOS and STAR, about $20 \%$ to streamer chamber analysis, and the remainder to other projects, notably the neutron flow experiment at the Bevalac, E848H (see section 5). Now that streamer chamber analysis and E848H running are no longer a factor, this part of the effort can be redirected to NA49. On the other hanu, after returning to teaching and service duties in the fall, and factoring-in the new workload associated with the HV control and monitoring project (section 3), a dilution of effort seems inevitable without at least a modest increase in manpower at Kent. The scenario being proposed is to share $50 \%$ of the effort of a new postdoc with Prof. Mark Manley. Miark Manley's experimental work is mainly in the area of electron scattering and is funded by NSF; he needs a 0.5 FTE postdoc to work on Bates and CEBAF-related hardware 
development, and his balf of the support for FY $92 / 93$ is available. The plan is to recruit a hardware-oriented person, possibly from a heavy ion background but maybe from another subfield of nuclear or high energy physics, and for this new postdoc to begin contributing to the PI's program by taking responsibility for much of the work on the HV project. Although this HV project is primarily motivated by the needs of STAR, it is sufficiently generic to benefit NA49 also; moreover, this scenario would allow the PI to devote more time to NA49.

One obvious project for the $\mathrm{PI}$ is to investigate the feasibility of $\mathrm{K}_{S}^{0}$ interferometry in the NA49 environment. Although the detected $K_{S}^{0}$ multiplicity will at best be much lower than at STAR, collisions at the SPS explore a more baryon-rich region than at RHIC, and this increases the chances for detecting an entirely new component of interference, having a connection with ustrangeness distillation" effects (see STAR note \#47 in the appendix, and references therein).

\section{Other Activities}

\subsection{The Neutron Flow Experiment E848H}

During July and August 1991, Prof. Dick Madey's neutron flow experiment E848H had its second major run (the first was in 1988). After a number of overnight tests, the experiment took data in the uninterrupted "block running" mode for more than three weeks, using Au, La and $\mathrm{Nb}$ beams at a variety of bombarding energies. In the 1988 run, we could record only the time-of-flight information in the case of most of the 184 elements of the plastic wall that serves to tag the orientation of the reaction plane for each event. A major improvement in the recent run was the added capability to record pulse height information for the entire wall; as documented in the PI's 1988 proposal, this reduces dispersion in the determination of the reaction plane.

It was necessary to dismantle the E848H setup after the 1988 run. Since then, the HISS cave has been lengthened by about 25 feet in order to accomodate the $\mathrm{E} 848 \mathrm{H}$ detectors with minimal disruption to (and from) the main part of the HISS facility, including the EOS TPC. A new dedicated $\mathrm{E} 848 \mathrm{H}$ electronics house bas also been provided. The VME data acquisition system used during the 1988 run was no longer available, and instead we used a system developed by Bill Rathbun for use at the 88-inch cyclotron at LBL. As a result of all these changes, a major effort was needed to prepare for the 1991 run, and the PI and all three students worked full time on these preparations during the month preceding the run. This experience was especially valuable for Jinghua Jiang, whose research to date (e.g., publications [i] and [vii]) has focused on analysis of data from older experimental runs in which she did not participate. 


\subsection{Collaboration with Harbin}

The collaboration with the group of Prof. Yiming $\mathrm{Li}$ : of the Harbin Institute of Technology, China, has continued to be very productive; two studies resulting directly from this collaboration that were described in last year's report, and were in the draft phase at that time, are now published (publications [iii] and [iv]). About half our collaborative work has taken the form of theoretical studies relating to the HBT effect, e.g., publications [iv] and [viii] (the latter explores the effect that iriplet and bigher-order HBT interference has on the interpretation of conventional pair HB' andyses, a question that has always been ignored in the past). We plan to continue this line of in vestigation in the future, with emphasis on understanding higher order HBT interference, a topic that is of increasing relevance and importance as the multiplicities of produced particles becomes higher. Prof. Shan Wang of Harbin is s sheduled to visit Kent for about 8 months beginning this fall, and this visit will facilitate plans for the Harbin group to diversify into new areas of experimental analysis such os the EOS TPC and/or E848H. 


\section{Publications for 12-Month Period Ending April 1992}

This section lists all work cosuthored by the PI having a publication date within the 12-month interval since last year's report; in the case of journal publications, papers in press or submited for publication are also listed. The abstracts for the $f$ ublished journal papers are reproduced in the Appendix, along with the full preprint for [vii]. An unpublished STAR report is also included in the Appendix.

\subsection{Papers in Refereed Journals}

[1] J. Jiang, D. Keane, J. Cogar, G. Fai, S. Bayanhi, C. Burtnack and H. Stöcker,

"Nuclear Thansport Models Can Reproduce Charged-Parlicie-Inclusive. Measurements But An Not Strongly Conutroined By Them".

Phys. Rev. C 43, 2353 (1991).

[ii] Abdulnasser F. Barghouty, George Fai, and Declan Keane,

"Pion Yields and Pion Spectra from Nwelear Collisions",

Nuel. Phys. A5\$5, 715 (1981).

[iii] S. Wasg, Y.Z. Jiang, Y.M. Liu, D. Keane, D. Beavis, S.Y. Cbu, S.Y. Fung, M. Vient, C. Bartnack, and B. Stöcker,

"Measurement of Collective Flow in Beavy Ion Collisions Uaing Particle-Pair Correlations", Phys. Rev. C 44, 1091 (1891).

[iv] Y.Z. Jiaug, L. Buo, Y.M. Liu, S. Wang, D. Kenne, S.Y. Chu, and S.Y. Fung,

"Spatial Information on the Pion-Emitting Sosrce from Pion Inte feronetry", Phys. Rev. C 44, 1857 (1891).

[v] D. Beavis, R. Bock, R. Brockmann, P. Danjelewicz, S.Y. Fung, J.W. Barris, D. Keane, Y.M. Liu, G. Odyniec, R.E. Renfordt, A. Sandova, D. Schall, R. Stock, H. Ströbele, M.A. Vient, "Collective Molion in ArtPb Collisions at Beam Energies between 100 and $1800 \mathrm{MeV} / \mathrm{nucleon}$ ", Phys. Rev. C 45, 299 (1982).

[vi] W.B. Christie, W.F.]. Mueller, D.L. Oloon, T.J.M. Symons, H.B. Wieman, D. Beavis, F.P. Brady, J. Romero, C.E. Tull, T. Abbott, S.Y. Fung, D. Keane, and Y. Liu, "Pion Correlations in 1.8 A GeV Ar on KCl awd on Land $1.2 \mathrm{~A}$ GeV Xe on La", Phys. Rev. C 45 (in preas).

[vii] J. Jieng, D. Besvis, S.Y. Chu, G. Fu, S.Y. Pung, Y.Z. Jieng, D. Keane, Q.J. Liu, Y.M. Liu, Y. Sheo, M. Vient, and S. Wang,

"Bigh-order Collective Flow Correlations in Beary-Ion Collisione",

Phys. Rev. Lett. 68 (in prese).

[viii] W.N. Zhnng, Y.Z. Jiang, S. Wang, Y.M. Liu, E. Keane, J. Jiang, Y. Sheo, S.Y. Fung, and S.Y. Chu, "Matti-pion Correlations is Twa-pion Interferometry",

Higot Ener. \& Nuel. Phyt. 16 (in preas).

[ix] Q.J. Liu, Y.Z. Jiang, S. Wang, Y.M. Liu, D. Keane, S.Y. Fung, and S.Y. Chu, "Mutti-particie Azimuthal Correlations and the Nuelear Equation of State", submitted to High Ener. \& Nucl. Phyw. 
[x] L. Buo, Y.Z. Jiang, S. Wang, Y.M. Liu, D. Keane, S.X. Fung, and S.Y. Cbu, "Spatial Parameter from Two-pion Interferometry",

submitted to High Ener. \& Nucl. Phys.

[xi] A.R. Baldwin, R. Madey, W..M. Zhang, B.D. Anderson, D. Keane, J. Varga, J.W. Wateon, G.D. Westfall, K. Frankel, and C. Gale "Inclusive Neatron Cross Sections from Ne.Pb Collisions at $790 \mathrm{MeV} / \mathrm{nucleon}$ ", oubmitted to Phys. Rev. C

\subsection{Conference Proceedings}

[a] D. Keane, J. Jiang, Y.Z. Jiang, Q.J. Liu, Y.M. Liu, S. Wang, S.Y. Chu, and S.Y. Fung, "Multi. Particle Correlations and the Nuclear Equation of State", Proc. of the 4th Conf. on Intereections between Particle and Nuclear Physics, Tuceon, Arirona, 1991, ed. W. Van Oers, (AIP, New York, 1882), p. 829.

[b] R. Madey, T. Eden, W.M. Zhang, B.D. Andenon, A.R. Bs. in, D. Keane, D.M. Manley, J.W. Watson, S. Kowalski, W. Bertozzi, G. Dodson, K. Dow, M. Farkhondeh, W. Korech, D. Tieger, W. Turchinetz, L. Weinstein, T. Reichelt, J.M. Finn, K. Beard, P. Markowitz, P. Rutt, R. Lourie, D. Barkhuff, S. Van Verat, C.C. Chang, J.J. Kelly, T. Payerle, J. Cameron, B. Ni, M. Spraker, 3. Mougey, P. Ulmer, R. Whitney, B. Flanders, P. Pella, C. Hyde-Wright, and W.-D. Jiang,

"Status of Bates Experiment 85.05: Tha Electric Form Factor of the Nestron from the d(e,e'n)p Reaction", Proc. of the 4th Conf. on Intersection between Particle and Nuclear Physica, Tucwon. Arizona, 1091, ed. W. Van Oers, (S.IP, New York, 1992), p. 954.

\subsection{Technical Reports \& Abstracts}

[a] R. Madey, T. Eden, W.M. Zhang, B.D. Anderson, A.R. Baldwin, D. Keane, D.M. Manley, J. Schambach, J.W. Watson, S. Kowelski, M. Farkbondeh, W. Sapp, L. Weinstein, J.M. Finn, P. Markowitz, R. Pourang, P. Ruth, W. Herrog, R. W. Lourie, C.C. Chang, J.J. Kelly, B. Ni, M.C. Spraker, P. Ulmer and R. Whitney, and P.J. Pells, "Feasibility Test of the $d\left(\bar{e}_{,} e^{\prime} \tilde{n}\right) p$ Reaction to Measure $G_{E}^{*}$ ", Bates Linear Accelerator Center Annual Scientific and Technical Report 1990, ed. W. Lobar, (1891).

[b] W. Christie, D. Olson, T. Abbott, D. Besvis, P. Brady, S. Fung, J. Kang, D. Keane, Y. Liu, W. Mueller, J. Romero, J. Symons, C. Tull, H. Wieman, "Pion Correlations in Relativiotic Beavy Ion Collisions at the Bevalec", Annual Report of Nuclear Science Diviaion, Lawrence Berkeley Laboratory, 1982 1990.

[c] M. Eleasar, J. Schembach, R. Madey, W. Zhang, D. Keane, B.D. Anderson, A.R. Buldwin, J.W. Watson, G. Westfall, G. Krebs, and H. Wieman, Bevalac Experiment E848B: Neutron Triple-Differential Cross Sections from Av-A* Collisions at 100 Ala eV*, Bull. Amer. Phys. Soc. 38, 2132 (1901).

[d] K. Kadija, G. Prajc, D. Vranic, F.P. Brady, J.E. Dreper, J.L. Romero, J.B. Carroll, V. Ghawikhanian, E. Gulmez, G.J. Igo, S. Trentalange, C. Whitten Jr., M. Cherney, S. Margetia, R.E. Renfordt, D. Röhrich, R. Stock, H. Ströbele, S. Wenig, T. Ballman, L. Madansky, B. Andereon, D. Kease, R. Madey, J. Watson, F. Bieser, M.A. Bloomer, D. Cebra, W. Christie, E. Friedlander, D. Greiner, C. Grubn, J.W. Harris, H. Buang, P. Jacobs, S. Kleinfelder, P. Lindstrom, H. Matis, C. MeParland, C. Naudet, G. Odyniec, D. Obon, A.M. Poblanzer, G. Rai, J. Rasmussen, B.-G. Ritter, 1. Sakrejda, J. Schambach, L.S. Schroeder, P.A. Seidl, T.J.M. Symons, S. Tonse, A. Wieman, W.K. Wilson, D.D. Carmony, Y. Choi, A. Hirsch, E. Ajort, N. Porile, R.P. Scharenberg, B. Srivastava, M.L. Tincknell, A.D. Chacon, K.L. Wolf, W. Dominik, M. Gazdricki, W.J. Braithwaite, J.G. 
Cramer, D. Prindle, T.A. Trainor, A. Breskin, R. Chechik, Z. Freenkel, A. Shor, and I. Twerruya, "Update to the RHIC Letter of Intent for An Experiment on Particle and Jet Production at Midrapidity, LBL-31040 (1991).

[e] P. Markowitz, K. Beard, J.M. Finn, P.M. Rutt, B. Flanders, J. Mougey, P. Ulmer, R. Whitney, P. Pella, J. Cameron, B. Ni, M. Spraker, R. Madey, T. Eden, W.M. Zhang, B.D. Andereon, A.R. Baldwin, D. Keane, D.M. Manley, J.W. Watson, S. Kowalski, W. Bertozzi, G. Dodson, K. Dow, M. Farkhondeh, W. Korsch, D. Tieger, W. Turchinetz, L. Weinstein, T. Reichelt, C.C. Chang, J.J. Kelly, T. Payerle, D. Barkhuff, R. Lourie, S. Van Verst, C. Hyde-Wright, and W.-D. Jiang, "The Magnetic Form Factor of the Nestron $G_{M}^{m}$ woing the (e,e'n) Reaction: Status of Bates Experiment 85-05", Bull. Amer. Pbye. Soc. 36, 2729 (1891).

[f] P.M. Rutt, K. Beard, J.M. Finn, P. Markowitz, B. Flanders, J. Mougey, P. Ulmer, R. Whitney, P. Pella, J. Cameron, B. Ni, M. Spraker, R. Madey, T. Eden, W.M. Zhang, B.D. Anderwon, A.R. Baldwin, D. Keane, D.M. Manley, J.W. Wateon, S. Kowalski, W. Bertozzi, G. Dodwon, K. Dow, M. Farkhondeh, W. Korsch, D. Tieger, W. Turchinetz, L. Weinstein, T. Reichelt, C.C. Chang, J.J. Kelly, T. Payerle, D. Barkhuff, R. Lourie, S. Van Verst, C. Byde-Wright, and W.-D. Jiang, "Deateron Momentum Distributions from (e,e'n) Measurements", Bull. Amer. Phys. Soc. 36, 2729 (1991).

[g] P. Markowitz, K. Beard, J.M. Finn, P.M. Rutt, B. Flanders, J. Mougey, P. Ulmer, R. Whitney, P. Peila, J. Cameron, B. Ni, M. Spraker, R. Madey, T. Eden, W.M. Zhang, B.D. Anderson, A.R. Baldwin, D. Keane, D.M. Manley, J.W. Watson, S. Kowalski, W. Bertozzi, G. Dodson, K. Dow, M. Farkhondeb, W. Korsch, D. Tieger, W. Turchinetz, L. Weinstein, T. Reichelt, C.C. Chang, J.J. Kelly, T. Pajerle, D. Barkbuff, R. Lourie, S. Van Verst, C. Hyde-Wright, and W.-D. Jiang, "Electromagnetic Structure of the Newtron: The Magnetic Form Factor $G_{M}^{m}$ using the (e,e'n) Reaction", Bull. Amer. Phys. Soc. 37, 884 (1082).

[h] P.M. Rutt, K. Beard, J.M. Finn, P. Markowitz, B. Flanders, J. Mougey, P. Ulmer, R. Whitney, P. Pella, J. Cameron, B. Ni, M. Spraker, R. Madey, T. Eden, W.M. Zhang, B.D. Anderson, A.R. Baldwin, D. Keane, D.M. Manley, J.W. Watson, S. Kowalski, W. Bertozzi, G. Dodson, K. Dow, M. Farkhondeh, W. Korsch, D. Tieger, W. Turchinetz, L. Weinstein, T. Reichelt, C.C. Chang, J.J. Kelly, T. Payerle, D. Barkhuff, R. Lourie, S. Van Verst, C. Byde-Wright, and W.-D. Jiang, "Recoil Nertron Momentum Distributions from the (e,e'n) Reaction", Bull. Amer. Pisys. Soc. 37, 884 (1992).

[i] M. Eleasar, R. Madey, W. Zhang, J. Schambach, D. Keane, B.D. Andereon, A.R. Baldwin, J.W. Watson, G. Westfall, G. Krebs, and B. Wieman, C. Gale, and K. Baglin, Bevalac Experiment E848B: Nentron TripleDifferential Cross Sections from Au + Av Collisions at 100A MeV", Bull. Amer. Phys. Soc. 37, 985 (1992). 
$\nabla$
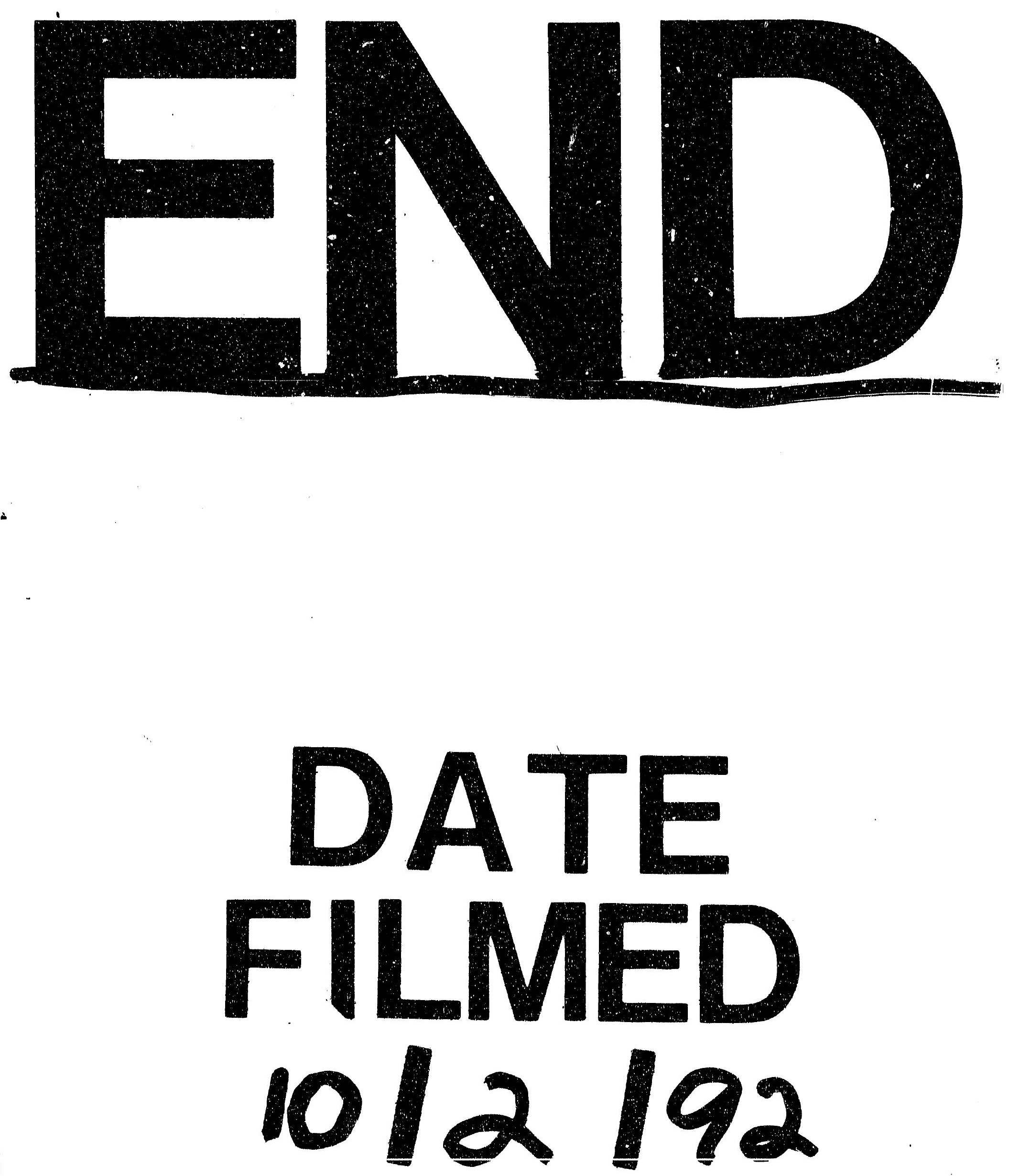
